\title{
EFFECT OF DIFFERENT COBALT CONCENTRATION ON PROPERTIES OF ELECTRODEPOSITED NiCoCr THIN FILMS
}

\author{
S. P. Meena ${ }^{1, *}$ and R. Ashokkumar ${ }^{2}$ \\ 1,*Research Scholar, Research and Development Centre, Bharathiar University, \\ Coimbatore-641 046, TamilNadu, India \\ ${ }^{2}$ Assistant Professor, PG and Research Department of Physics, Thiruvalluvar Govt. Arts College, \\ Rasipuram-637 401, TamilNadu, India \\ *E-mail: meenaphysics2012@gmail.com
}

\begin{abstract}
Magnetic thin films of $\mathrm{NiCoCr}$ have been prepared using electrodeposition in various cobalt concentration. $\mathrm{NiCoCr}$ deposited thin films are textured with face-centered cubic phase orientation. Experimentally observed soft magnetic property of thin films for different cobalt concentration was compared.The addition of cobalt sulphate (Co) can enhance coercivity and mechanical properties of NiCo thin films. Electrodeposited NiCoCr films were prepared at different cobalt sulphate concentration (10, 20, 30 and $40 \mathrm{~g} / \mathrm{l})$ and they were undergone to morphological, structural characters, magnetic and mechanical (hardness) characterization analysis. Cobalt content was maximum as 46.37 wt $\%$ at $40 \mathrm{~g} / \mathrm{l}$ cobalt sulphate concentration. The chromium content increased when the concentration of cobalt was increased. NiCoCr films were bright and uniformly coated on the surface. Also the deposits of $\mathrm{NiCoCr}$ films were in nano scale and the average crystalline size was around $28 \mathrm{~nm}$. Thin films prepared at high cobalt concentration exhibited a high saturation magnetization and high coercivity. The micro hardness of NiCoCr was $91 \mathrm{VHN}$ at $40 \mathrm{~g} / \mathrm{l}$ cobalt sulphate concentration
\end{abstract}

Keywords: electrodeposition, electrolytic bath, crystalline size, VSM, X-ray diffraction, VHN, SEM.

C $\mathrm{RASA} Y \mathrm{YN}$. All rights reserved

\section{INTRODUCTION}

Attractive magnetic thin films have pulled in much consideration because of their potential applications in small size electric components, for example, radiofrequency thin film inductors and read/write heads of a computing machine. Iron, nickel, cobalt and their alloys are common attractive soft and hard magnetic materials relevant to delicate and anisotropic magneto resistance (AMR) ${ }^{1-4}$. Conventional Ni-Co alloy are vital soft magnetic materials which have been broadly and commercially utilized in the industry since it has an excessive coercive field, high saturation magnetization, high electric permeability and low eddy

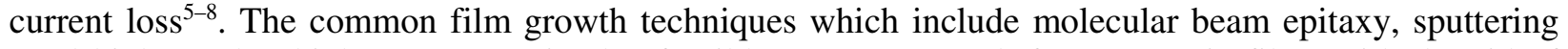
need high or ultra-high vacuum. It is also feasible to prepare such ferromagnetic films with the aid of electroplating, which does not require any vacuum device ${ }^{9-12}$. Furthermore, it has more benefits like efficient coating, extra portions of materials coatings and effective control of electro deposition parameters. In this article, the surface, chemical composition and magnetic characterization of electro deposited NiCoCr films have been investigated with changing cobalt concentration.

\section{EXPERIMENTAL}

The electroplated NiCoCr alloy films were synthesized for the different content of cobalt 10, 20, 30 and $40 \mathrm{~g} / \mathrm{l}$. The timing of deposition process was 15 minutes. In this experiment, $\mathrm{Cu}$ and stainless steel substrates acted as cathode and anode respectively with $1.5 \mathrm{~cm}$ x $7.5 \mathrm{~cm}$. dimension ${ }^{13}-15$. The $\mathrm{NiCoCr}$ thin films were prepared from electrolytic solution which contain $\mathrm{CoSo}_{4}(10,20,30$ and $40 \mathrm{~g} / \mathrm{l}$ 1), NiSo 4 $(30 \mathrm{~g} / \mathrm{l}),(\mathrm{Cr})_{2}(\mathrm{So} 4)_{3}(10 \mathrm{~g} / \mathrm{l})$, Ammonium $\left(\mathrm{NH}_{4}\right)_{2} \mathrm{SO}_{4}(40 \mathrm{~g} / \mathrm{l})$ and $\mathrm{C}_{6} \mathrm{H}_{8} \mathrm{O}_{7}(10 \mathrm{~g} / \mathrm{l})$. The $\mathrm{pH}$ value of the electrolytic solution was 6.0 by mixing $\mathrm{NH}_{3}$ solution and electroplating process was carried out with current density $2 \mathrm{~mA} / \mathrm{cm}^{2}$. The Cu plate was removed from the electrolytic bath after $15 \mathrm{~m}$ and dried out 
for few seconds ${ }^{16-18}$. The coating surface of NiCoCr films was characterized by Scanning Electron Microscope .The elemental content of deposits of films was investigated by EDX Spectroscopy and crystal formation of deposits was analyzed by X-ray diffraction study. The micro hardness of films was calculated by Vicker's Hardness Test. The important magnetic properties of deposits are saturation magnetization and coercivity .Analysis of thin films with Vibrating Sample Magnetometer gives magnetic properties $^{19-21}$.

\section{Chemical Composition - NiCoCr Thin Films}

\section{RESULTS AND DISCUSSION}

EDS data of obtained magnetic films are shown in Table-1. EDS result indicates that the films received with a higher concentration of cobalt sulphate have high cobalt content. The high cobalt content of $46.37 \mathrm{wt} \%$ was received for $40 \mathrm{~g}$ concentration of cobalt sulphate. EDS result shows that nickel content decreases with increasing content of cobalt sulphate. The weight percentage of chromium increases while increasing concentration of cobalt sulphate.

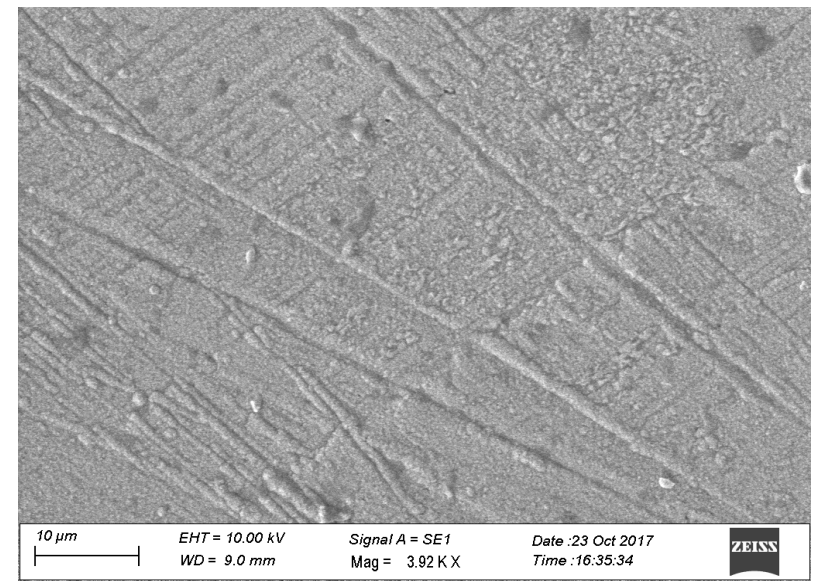

(a)

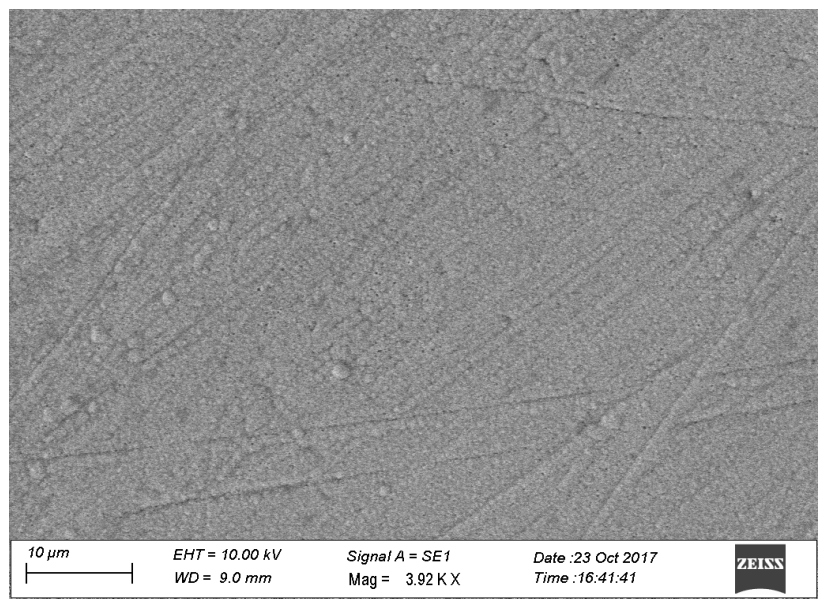

(c)

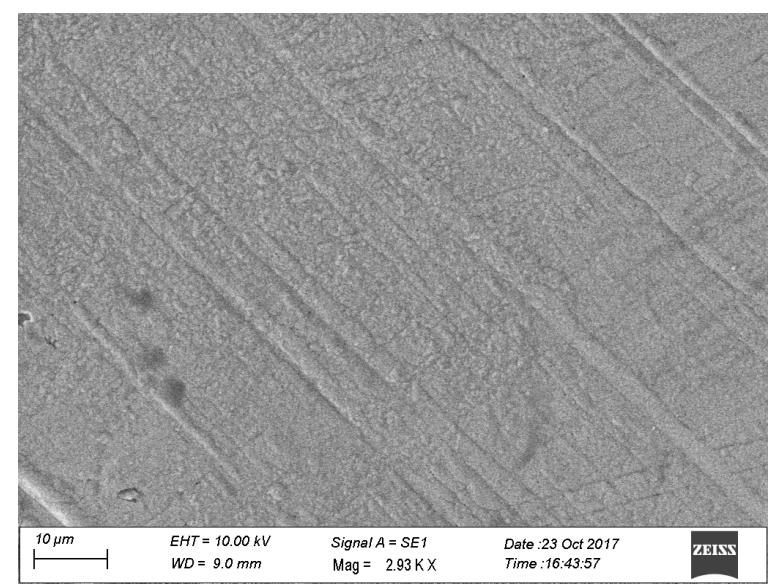

(b)

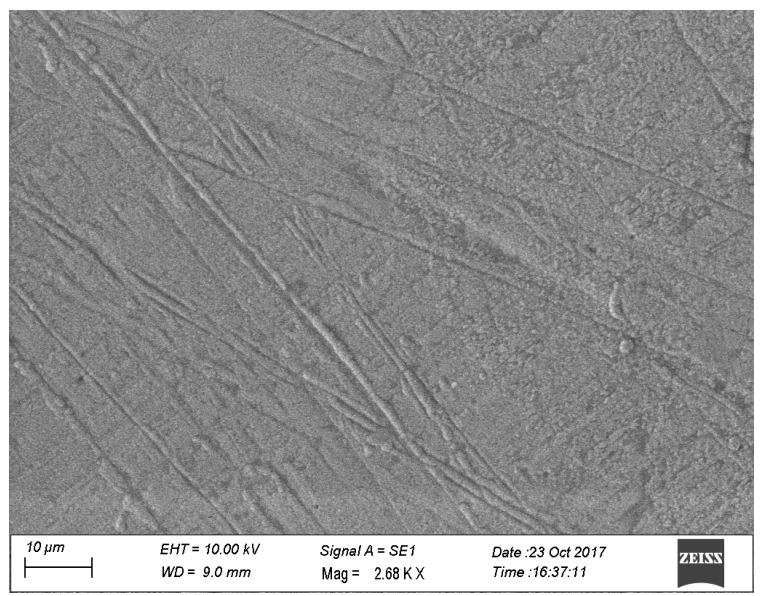

(d)

Fig.-1: SEM pictures for Electrodeposited Ni-Co-Cr film for the concentration of cobalt sulphate (a) $10($ b) $20(c) 30(d) 40 g$

\section{Morphological Observation}

The surface study of the Ni-Co-Cr alloy thin films with different content of cobalt sulphate was done by Scanning Electron Microscope and SEM pictures are shown in Fig.-1.The electroplated 
thin films appears without cracks and uniform. They are bright in nature. It concludes that the deposition of materials on the substrate is uniform.

Table-1: EDS Analysis of thin Films

\begin{tabular}{c|c|c|c|c}
\hline S. No. & $\begin{array}{c}\text { Cobalt } \\
\text { Concentration(g/l) }\end{array}$ & $\begin{array}{c}\text { Co } \\
\mathrm{Wt} \%\end{array}$ & $\begin{array}{c}\mathrm{Ni} \\
\mathrm{Wt} \%\end{array}$ & $\begin{array}{c}\mathrm{Cr} \\
\mathrm{Wt} \%\end{array}$ \\
\hline 1. & 10 & 31.04 & 54.15 & 14.81 \\
\hline 2 & 20 & 36.28 & 47.26 & 16.46 \\
\hline 3 & 30 & 40.95 & 41.28 & 17.77 \\
\hline 4 & 40 & 46.37 & 35.72 & 17.91 \\
\hline
\end{tabular}

(a)
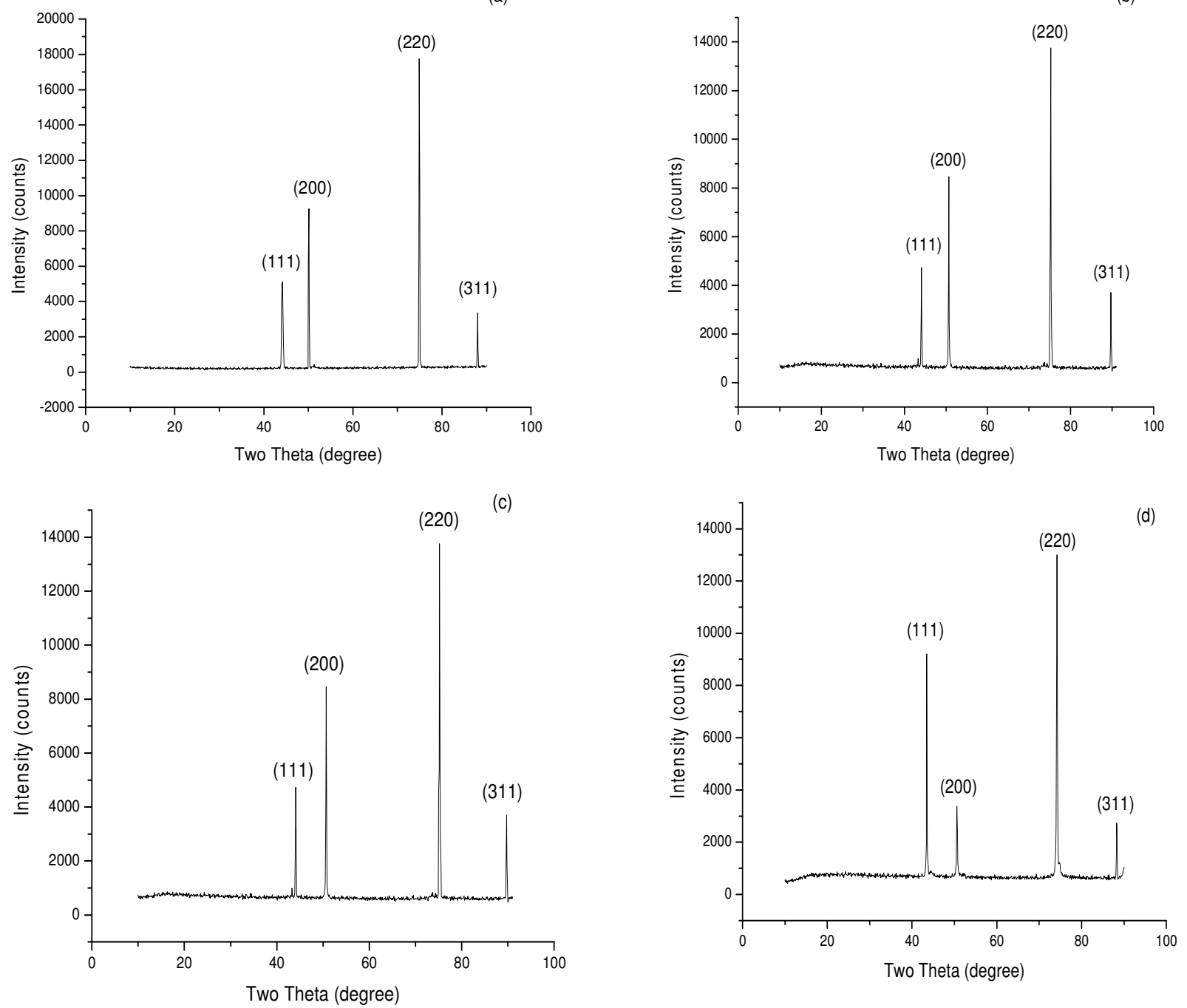

Fig.-2 : XRD graphs of Ni-Co-Cr films for different concentration of cobalt sulphate (a) 10 (b) 20 (c) 30 (d) $40 \mathrm{~g}$

\section{Structural Analysis}

The crystal structure of Ni-Co-Cr alloy thin films was determined by XRD investigation. Fig.-2 displays XRD analysis patterns of the Ni-Co-Cr alloys electrodeposited from the electrolytic bath. The XRD studies show that electrodeposited magnetic alloys have different crystal orientations. XRD peaks of the 
alloys show a preferred orientation along the (111), (200), (220), and (311) planes. From XRD pattern, average grain size values of the alloys were calculated using the peak width at the half maximum using Scherer method:

Where, $\beta$ - FWHM intensity,

$$
\mathrm{D}=0.954 \lambda / \beta \cos \theta
$$

$\lambda$--X-ray wavelength

$\theta$-- Bragg's angle of the diffraction peak. Obtained result shows that $\mathrm{Ni}-\mathrm{Co}-\mathrm{Cr}$ deposits are in the nano structured and the average crystallite size is around $28 \mathrm{~nm}$.

The particle size, dislocation density and strain of Ni-Co-Cr alloy films are shown in Table-2.When the cobalt sulphate concentration is $40 \mathrm{~g}$, the crystalline size of thin film is $42.74 \mathrm{~nm}$.

Table-2: Structural characteristics of Ni-Co-Cr alloy thin films

\begin{tabular}{c|c|c|c|c|c|c}
\hline S. No. & $\begin{array}{c}\text { Cobalt } \\
\text { Concentration } \\
(\mathrm{g} / \mathrm{l})\end{array}$ & $\begin{array}{c}2 \theta \\
(\mathrm{deg})\end{array}$ & $\begin{array}{c}\mathrm{d} \\
\left(\mathrm{A}^{0}\right)\end{array}$ & $\begin{array}{c}\text { Particl } \\
\mathrm{e} \\
\text { Size }(\mathrm{D}\end{array}$ & $\begin{array}{c}\text { Strain } \\
\left(10^{-3}\right)\end{array}$ & $\begin{array}{c}\text { Dislocation } \\
\text { Density } \\
\left(10^{14} / \mathrm{m}^{2}\right)\end{array}$ \\
\hline 1 & 10 & 76.27 & 1.290 & 17.86 & 2.027 & 31.35 \\
\hline 2 & 20 & 74.05 & 1.266 & 22.65 & 1.591 & 19.49 \\
\hline 3 & 30 & 75.19 & 1.304 & 30.18 & 1.201 & 10.98 \\
\hline 4 & 40 & 76.63 & 1.255 & 42.74 & 0.847 & 05.47 \\
\hline
\end{tabular}

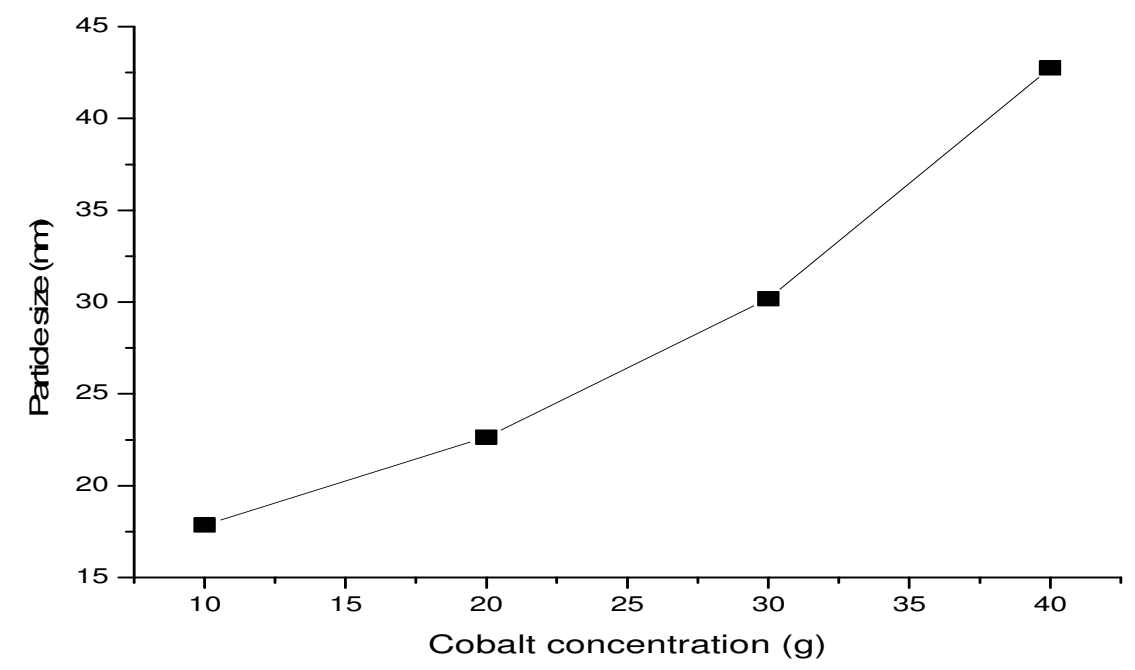

\section{Mechanical Properties}

Fig.-3: Crystalline Size as a function of cobalt concentration

Micro hardness analysis of deposits has been done by Vickers hardness tester. The hardness values of thin films prepared with increasing cobalt sulphate concentration are 44,69,74,91 VHN respectively. So it is concluded that the hardness increases with increasing cobalt sulphate due to the lower strain associated with thin films. Fig.-4 indicates the variation of hardness with increasing cobalt sulphate.

\section{Magnetic Characterization - NiCoCr Thin Films}

The magnetic characters of Ni-Co-Cr thin films have been found from VSM and they're tabulated in Table-3.The hysteresis loops of Ni-Co-Cr films with various content of cobalt sulphate are shown in Fig.-5.The film coated with $40 \mathrm{~g}$ of cobalt sulphate exhibits the higher coercivity $\left(\mathrm{H}_{\mathrm{s}}\right)$ and magnetization $\left(\mathrm{M}_{\mathrm{s}}\right)$. It was observed that $\mathrm{M}_{\mathrm{s}}$ increases from $0.217 \times 10^{-3} \mathrm{emu} / \mathrm{cm}^{2}$ to $14.240 \times 10^{-3} \mathrm{emu} / \mathrm{cm}^{2}$. 
From VSM result, it is concluded that films prepared at a high concentration of cobalt sulphate exhibits a higher value of saturation magnetization and high coercivity.

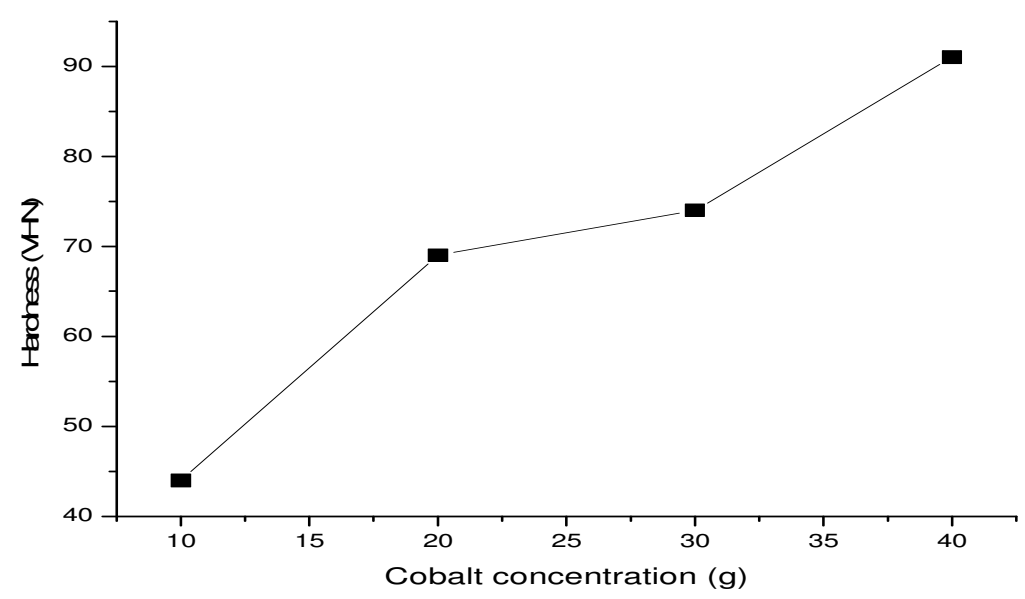

Fig.-4: Vickers Hardness as a function of cobalt sulphate concentration

Table-3: Soft Magnetic Properties of Ni-Co-Cr deposits

\begin{tabular}{c|c|c|c|c|c}
\hline S. No. & $\begin{array}{c}\text { Cobalt } \\
\text { Concentration } \\
(\mathrm{g} / \mathrm{l})\end{array}$ & $\begin{array}{c}\text { Coercivity } \\
\mathrm{H}_{\mathrm{s}}(\mathrm{G})\end{array}$ & $\begin{array}{c}\text { Magnetization } \\
\mathrm{M}_{\mathrm{s}}\left(\mathrm{emu} / \mathrm{cm}^{2}\right) \\
10^{-3}\end{array}$ & $\begin{array}{c}\text { Retentivity } \\
\mathrm{M}_{\mathrm{r}}\left(\mathrm{emu} / \mathrm{cm}^{2}\right) \\
10^{-3}\end{array}$ & $\begin{array}{c}\text { Squareness } \\
\left.\mathrm{S}_{(\mathrm{r}} / \mathrm{M}_{\mathrm{s}}\right)\end{array}$ \\
\hline 1 & 10 & 231 & 0.217 & 0.001 & 0.0046 \\
\hline 2 & 20 & 437 & 1.592 & 0.853 & 0.5358 \\
\hline 3 & 30 & 552 & 8.832 & 6.417 & 0.7265 \\
\hline 4 & 40 & 814 & 14.240 & 7.036 & 0.4941 \\
\hline
\end{tabular}

Magnetic materials with higher magnetization is a needed character of soft thin films. The magnetic properties of ferromagnetic materials are decided by crystalline size and movement of the domain wall. If the grain size is in terms of $\mathrm{nm}\left(10^{-9}\right)$, magnetic properties of deposits are enhanced. Crystalline sizes of the thin film have an important role to decide the coercivity and magnetization. It was noted that retentivity increase from $0.001 \times 10^{-3} \mathrm{emu} / \mathrm{cm}^{2}$ to $7.036 \times 10^{3} \mathrm{emu} / \mathrm{cm}^{-2}$.Magnetic properties of the films are also decided by different factors such as film strain and impurities etc.
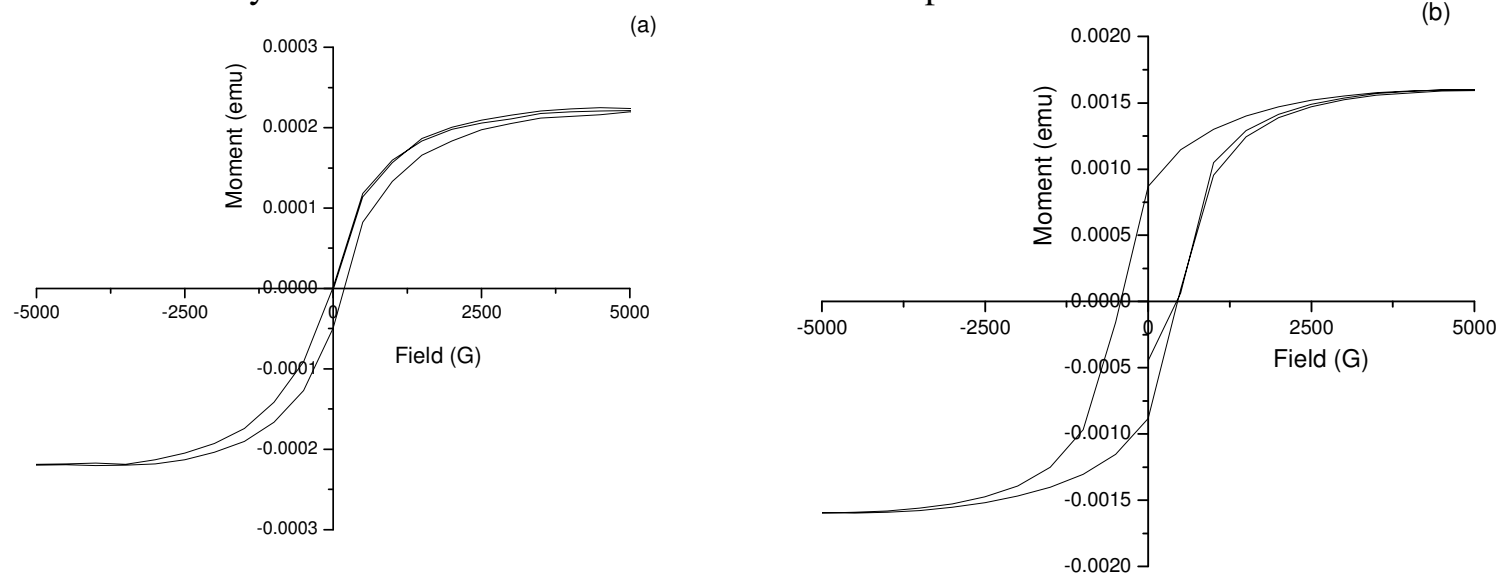
RASĀYAN J. Chem.

Vol. 11 | No. 2 |766 - 772 | April - June | 2018
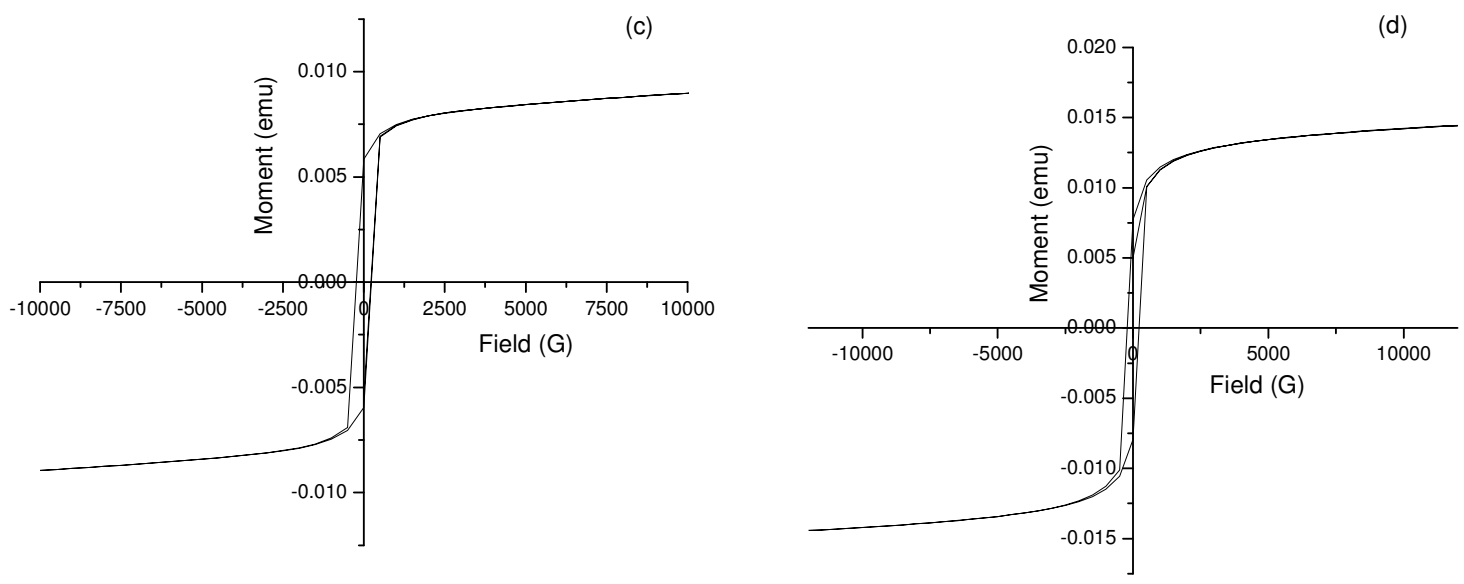

Fig.-5: Hysteresis loops for the Ni-Co-Cr thin magnetic film for the concentration of cobalt sulphate (a) $10(\mathrm{~b}) 20(\mathrm{c}) 30(\mathrm{~d}) 40 \mathrm{~g}$

\section{CONCLUSION}

The structural, magnetic, mechanical and morphology of $\mathrm{Ni}-\mathrm{Co}-\mathrm{Cr}$ thin films have been analyzed by varying the concentration of cobalt sulphate $(10,20,30$, and $40 \mathrm{~g})$ at $30^{\circ} \mathrm{C}$ for 15 minutes. The crystalline size increases with increasing concentration of cobalt sulphate. The thin films obtained with a different concentration of cobalt sulphate are uniform, bright and crack free. FCC was the dominant structure of $\mathrm{Ni}-\mathrm{Co}-\mathrm{Cr}$ alloy thin films. Micro hardness increases with increasing concentration of cobalt sulphate. When the concentration of cobalt sulphate was increased from 10 to $40 \mathrm{~g}$, the particle size values increase from $17.86 \mathrm{~nm}$ to $42.74 \mathrm{~nm}$. This happens because of nano structure crystal formation and low film strain related to Ni-Co-Cr alloy thin films. When the concentration of cobalt sulphate was increased from 10 to $40 \mathrm{~g}$, the magnetization values increases from $0.217 \times 10^{-3} \mathrm{emu} / \mathrm{cm}^{2}$ to $14.24 \times 10^{-3} \mathrm{emu} / \mathrm{cm}^{2}$. This is due to nano crystalline structure of deposits. The Ni-Co-Cr thin films can be used as radiofrequency thin film inductors and computer read/write heads.

\section{REFERENCES}

1. R. Celine and F.Patrick, J. Mater .Sci., 46, 6046(2011), DOI: 10.1007/s10853-011-5566-9

2. M. Ghorbani, A. Dolati and A. Afshar, Russian Journal of Electrochemistry, 38, 1173 (2002), DOI: 10.1023/A:1021141524584

3. K. Baonkeup and Y. Bongyoung, Surf. Coat. Technol., 205, 740 (2010), DOI:10.1016/j.surfcoat.2010.07.076

4. V. Nosang, D.Y. Park, B.Y. Yoob and T.A. Paulo, J. Magn. Magn Mater., 265, 189(2003), DOI:10.1016/S0304-8853(03)00264-6

5. S. Iwasaki and Y. Nakamura, J. Magn. Magn Mater., 200, 634(1977).

6. H. J. Cho, S. Bhansali and C. H. Ahn , J.Appl. Phy., 87, 6340(2000), DOI: 10.1063/1.372699

7. X.H. Yan, J.Q. Sun, Y.W. Wang and J.F. Yang, Journal of Molecular Catalysis A: Chemical., 252, 17(2006), DOI:10.1016/j.molcata.2006.01.060

8. N. Sulztanu and J. Fbrinza, J. Optoelectron. Adv. Mat., 6, 641(2004).

9. M. Bedir, O.F. Bakkaloglu, I.H. Karahan and M. Oztas, Pramana, 66(6), 1093(2006).

10. R.Kannan, R. Kanagaraj and S.Ganesan, Journal of Ovonic Research, 9, 45(2013).

11. Z .Shi, K. Deng and L. Li , Sci Rep., 5,9317 (2015), DOI:10.1038/srep09317

12. N. Gupta, A. Verma, and S.C. Kashyap, Solid State Commun., 10, 689(2005). 
RASĀYAN J. Chem.

Vol. 11 | No. 2 |766 - 772 | April - June | 2018

13. L. Chih-Huang, H. Matsuyama, R.L. White and T.C. Anthony, IEEE Transactions on Magnetics., 31(6), 2609(1995), DOI:10.1109/20.490068

14. K. Sridharan and K. Sheppard, J. Appl. Electrochem., 27, 1198(1997), DOI:10.1023/A:1018475718629

15. R.Kannan, S. Ganesan and T.M. Selvakumari, Digest Journal of Nanomaterials and Biostructures., 7, 1039(2012).

16. X. F. Meng, D. H. Li, X. Q. Shen and W. Liu, Applied Surface Science, 256, 3753(2010), DOI: $10.1016 /$ j.apsusc.2010.01.019.

17. S. L. Wang, Surf. Coat. Technol., 186, 372(2004), DOI: 10.1016/j.surfcoat.2004.01.017

18. Z. A. Hamid, Materials Letters., 57, 2558(2003), DOI: 10.1016/S0167-577X(02)01311-3

19. I. Giouroudi, A. Ktena, and E. Hristoforou, J. Optoelectron. Adv. M., 6, 661-666(2004).

20. E. Jartych, M. Jalochowski and M. Budzynski, Appl. Surf. Sci., 193, 210(2002).

21. S. Sam, G. Manavalan, A. Guittoum, N. Gabouze and S. Djebbar, Surf. Sci.,601, 4270(2007), DOI: $10.1016 /$ j.susc.2007.04.107

[RJC-3025/2018] 